\title{
Learning Analytics Dashboard to Improve Students' Performance and Success
}

\author{
Ghaniya Ahmed Al Hadhrami \\ Computing, Middle East College, Muscat, Oman, ghaniya@mec.edu.om
}

\begin{abstract}
Several learning researches have been conducted recently in order to improve the students' performance. The new learning system has benefited from numerical environment by presenting an online educational system. Structured approach in design, implementation, and student's assessment has been studied. The present project aims to develop a dashboard for "Learning Analytics Techniques to Improve Students' Performance and Success" through a web Application. The model proposed is a result oriented and aims to improve the online educational systems for both teachers and students. It includes more accurate assessment and more effective evaluation of the learning process. Learning analytics is focusing on data that coming from Learning Management System (LMS). The data coming from LMS includes the number of times the student has logged into the page, the assessment of the student according to course prerequisites, the time spent by the student in reading the course materials and the time taken to complete the module assessments and attending discussions on forum. This technique will show a visual report and explain where the student is lacking.

This framework will display the learning capacity of students to the teacher as well as the self-performance to the student. This project is designed with Data Mining techniques to identify student's risk and forecast student's results.
\end{abstract}

Keywords: learning analytics, dashboard, web Application, Learning Management System, Data Mining.

\section{Introduction}

Teachers are a significant asset for the educational process. They are spearhead of educational success and regarded hold important role in achieving educations aim. Teachers need the feedback of their teaching and learning mechanisms to confine the learning system. Learning Management System is the most common format for the teaching online. For example Moodle, it has several features and services, like upload course materials, videos, sound recordings, links, quizzes online, various other activities, assignment submission, discussion forum, files upload/ download capacity, grading, online calendar and etc. But Moodle faces some problems; it is not tracking and improving the student's performance. And at the same time, the student didn't know his/ her performance and the time spending on each activity. Some researchers have questioned the ability of feedback developed via dashboards to provide useful information to learners. Such representations of student activity are often incomplete due to the fact that not all aspects of the learning process can be captured by such means. There is also concern about the heavy reliance on quantitative representations of student activity through dashboards. Research on effective feedback to support self-regulated learning suggests that feedback needs to deliver high quality information to students that encourages dialogue with teachers and peers around learning. The extent to which students are able to use dashboards to facilitate such dialogue is an area that requires further exploration. One way that feedback can be delivered to student using learning analytics is in the form of a dashboard through which multiple sources of data can be visualized in a consolidated view. Feedback delivered through learning analytics dashboard s can provide students with data on their performance as well as their engagement on the learning design of the subject. Currently, there is very limited research to student in this format. However, this study considers the detail of how students interpreted and responded to the feedback mechanism and its impact on their learning strategies and motivation.

In order to solve this issue, a learning analytical tool with integrated dashboard based on a solution called quality in education system can improve education quality of the learning process. This learning system with different modes will assess and analyze the performance of students. New learning systems are designed with online access. They support activities and other course materials. Teachers need to know the progress of students in the activities and give feedbacks to them. This teacher-student relationship should be effectively transposed from traditional system to online one. Furthermore, many analytical tools can be integrated in the numerical platform to enhance the quality of the teaching and reduce the time spent on administration. It can enable every learner to achieve his or her potential and help to build an educational environment granted to change. This learning system is implemented as a portal in which it will be possible to add a student, upload a file, and add a course, a department and a subject. It will be also possible to generate reports based on learning analytics which play a vital role in enhancing the students' performance and increase their successes. Online Learning represents an innovative shift in the field of learning, providing rapid access to specific knowledge and 
information. It offers online instruction that can be delivered anytime and anywhere through a wide range of electronic learning solutions such as Web-based courseware, online discussion groups, live virtual classes, video and audio streaming, Web chat, online simulations, and virtual mentoring. It enables organizations to transcend distance and other organizational gaps by providing a cohesive virtual learning environment. [1].

Researchers and practitioners from many disciplines i.e., Statistics, behavioral science, cognitive psychology, education and computer science are been used to define and establish learning analytics as a discipline. The emerging field of learning analytics involves the analysis of data about learners and their activities to inform the enhancement of teaching and learning practices and environments. Online learning has several opportunities to exploit the use of technology. The technology will help to support the learning activities by gathering the data of the learning courses that may use in the assessments. While the students are using the system, the system can hold their involvements and gather the structures of problem solving, knowledge and planning in which used on it. This reflects and stores all information of each student in details who is visit, input, solve some activities and number of attempts that the students made on the course learning and number of the given feedbacks and how amount of time they spend on the activities learning [2].

Without entering the data the analytics cannot be completed. So the educational of data mining considers as the main important part of it. Emphasizing of educational Data mining through evolving the new algorithms and tools that help to make the detecting of data patterns but learning analytics through implementing the tools and techniques that suitable to the system needs. But because we want to have an analysis of the college, as it can improve the teaching and learning data mining analysis and personalized education, and how the process works. Any institution has its aim to improve its education and do the analytics that helps to increase the students' retention, enhance its service and to raise the grade of students [3]. But how educational data mining can help in the analysis of findings and study? The figure will display the answer in the best way which shown below:

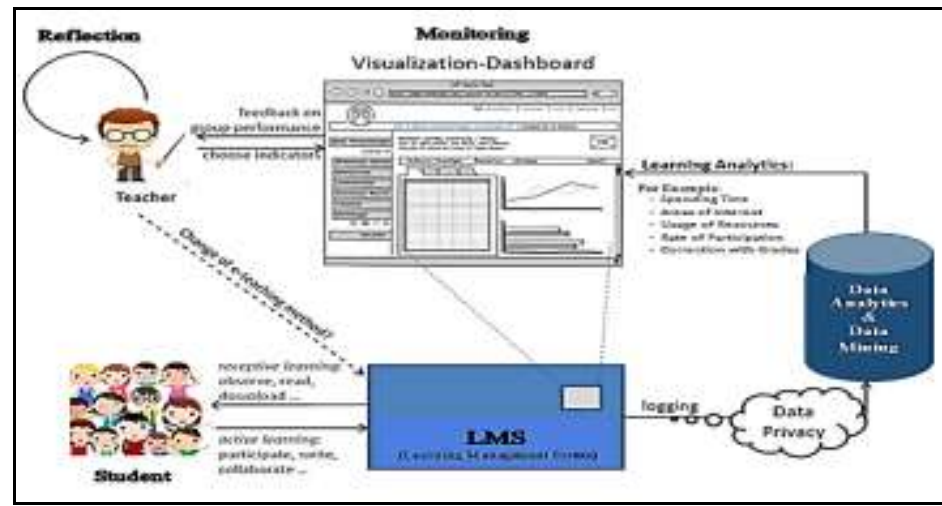

Fig. 1 Enhancing Teaching and Learning through Educational Data Mining and Learning Analytics

\subsection{LEARNING ANALYTICS: SOLUTIONS TO IMPROVE STUDENTS' SUCCESS RATES}

Initial learning analytics research has primarily focuses on providing data to academic staff on student engagement and performance, most commonly for the purpose of student retention. Feedback is a key element in students' self-regulation of learning as it enables students to monitor their progress towards their learning goals and to adjust their strategies to attain these goals.

\section{Problem Statement}

The paper targets to solve the problem of producing meaningful, accessible and timely information. This has found a main necessity in higher education system. The pressure to provide management information is growing. Most institutions are under intense pressure to maximize student retention and shorten time to graduation. Institutions are increasingly using the information they accumulate about their students to gain insight into big issues, such as academic performance, student success, persistence and retention. Regulatory bodies, accreditation bodies, state agencies and boards all are asking for more information to measure and evaluate the effectiveness of institutions. Decreases in state aid to higher education are causing many public institutions to pursue alternative revenues streams. To sort these issues it is observed that there certain issues that are to be considered. The major drawback comes into picture when the student is not assessed before starting course work using prerequisites of course. It is also required to assess the time period taken by the student while understanding the concept and also time taken to address the assessment of the course. If proper assessment is not performed using analytical tool, then there is a reason for a student to fail or drop out from the course apart from the personal issues, financial issues, health problems, time management, under preparation etc. of the student. This problem can be handled by learning analytical tool, which can continuously provide the 
report of assessment as a feedback to mentor to assess and understand that, is the student is slow learner, mediocre and fast learner accordingly the adjustment in curriculum can be performed.

\section{Research Aims And Objectives}

The rational of this research is to, design and define a learning analytical tool that provides visual report to facilitate in decision making process using different levels of the learners' cultures and lead to improvements of learning systems. In this system, the analysis of the individual student's data to determine the creditability of the student that can be monitored and defined after assessing, this data helps to improve the performance of the student during the learning process. This project is implemented using database retrieving tool as back end and a front end user friendly tool to understand and generate the reports, to represent the performance assessment mechanism. The proposed project will offer the suitable tools to evaluate the learners' performing and learning process, analyze the students' knowledge by obtaining the report by performing the prerequisite assessment test, assess the learning capability of the student, i.e., is he a slow learner, mediocre, slow learner by considering metrics to evaluate, provide feedback to the teacher about the student as such the strategies and models to be followed by the teacher can be changed, provide a dashboard that consist all the assessment report that required tracking the performance and to provide basic statistics on attendance, track time-on-task on online activities, participation rates in forums, performance on the online quizzes, test and marks on formal written assignments as well as exams and to reflect on teaching learning process by monitoring and analyzing their access to learning resources.

\section{Methodology}

In the present paper Modify Waterfall methodology has been used which is represented in Fig. 2. This methodology has five phases where each phase intended to have its own properties. As initially it has to understandable the environment that are the system are going to be installed in matter of the capability, student awarding level in how they catching up with electronically interface control panel. The second phase is the designing, this phase is very important in such of maintaining the at activity interface, the easiness's of the system usage, link speed for the portal to be view, the transaction process for functional and non-functional, strategy for maintaining the backup and other parameter that intended to the system. Also to design a low level structure to be followed fir the next phase.The Third, Fourth and Fifth phases are implementation, testing and maintenance. Implementation process is an intended evaluation, which is the combination of the gathered component to be work with each other, preparing the underline infrastructure to be allowing the system for hosted on and forming a strategy on how the system will be executed. In testing phase, which is also known as verification phase, the testing of whole parts of the system from all directions is done, like checking the ability to accept information system by entering the data. For example, enter username and password for three target of people (Administrator, teacher and student), course material including assessments and activities (quizzes, exercises, ..etc). In the maintenance phase the problems appearing in the user environment were sorted out. So it is required to take the opinion from the user if there is a problem in the system like, speed and capacity of data storage. And how the user deals with new system and how the student gets the tracking of her/his performance on the dashboard.

\subsection{HYPOTHESIS}

The goal of using learning analytics dashboard is to motivate the learner behaviors and examine what factors that supports to encourage the students to learn in the good manner. So the structural relationship within design and learners factors related to the efficiency in the learner perception. It includes usefulness of the information, effective visualization, easy to use, understanding level, reflective use, perceived effectiveness and behavioral engagement. The benefit to display the Hypotheses Model is to support and make the project strong. The figure which shown below will display the suitable model of hypothesize [4], [5]:

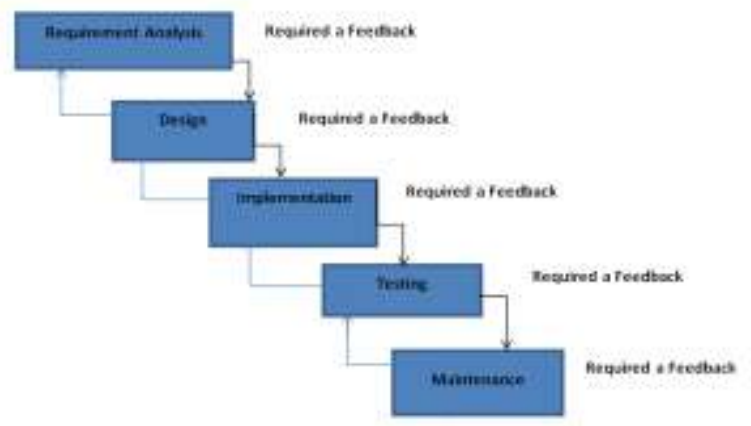

Fig. 2 Modified Waterfall Methodology 


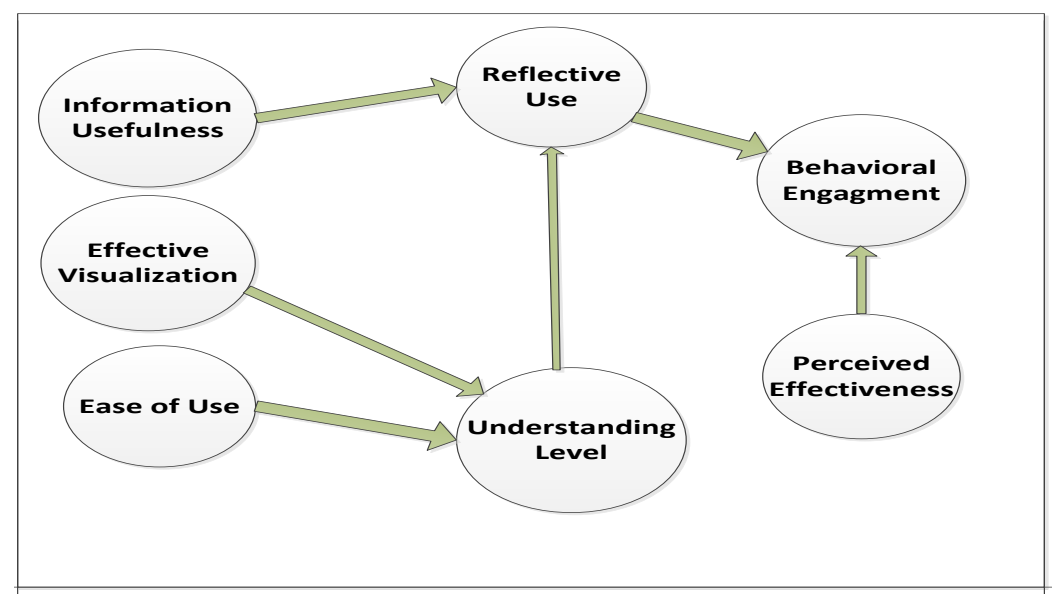

Fig. 3 Hypotheses of Research

\subsection{Data COLlection}

The method used in the present paper to gather the information was survey and interview. The sample size of the survey is 140 persons only. As survey is not for common people, it is related to people involved in the educational field, like teachers, student and administrators. The required information must be accurate so the distribution of the survey will be done to students and teachers too.

\section{Finding And Discussion}

Survey Result: The two online distributions of the survey were about Learning Analytics Dashboard to Improve the Students' Performance and Success. And receive a large number of responses, which was specialized for a certain category of people who are Teachers, Administrators and Students gathered important information from these categories. One of these surveys was for Teachers and Administrators which conducted with several departments in College and University. The data gathering was useful and gaining with good knowledge. The result that given from conducting the survey was really good. Most of the despondences were agree to use this new tool that help and motivate the student's performance and all the responses showed in Fig. 4.This question is asked to find out the percentage of Lack awareness relating to learning course by the student followed the educational system in college can be rectified by online learning system. The result showed that 49\% are strongly agree comparing to only $\mathbf{1 3 \%}$ strongly. The remaining responses are presented in the figures below: And another of the question shows that the design of dashboard technique to online learning system will impact on learning process. The responding represent around $\mathbf{2 2 . 2 2 \%}$ are strongly agree, $\mathbf{6 6 . 6 7 \%}$ are agree, $\mathbf{5 0 \%}$ are strongly disagree and $\mathbf{0 0 . 0 0 \%}$ are disagree. Therefore, the analyzing for this part using dashboard technique will help to improve the learning and open the doors for all students to know their performance into the activities that they participate and build the good relations between the teachers and students.

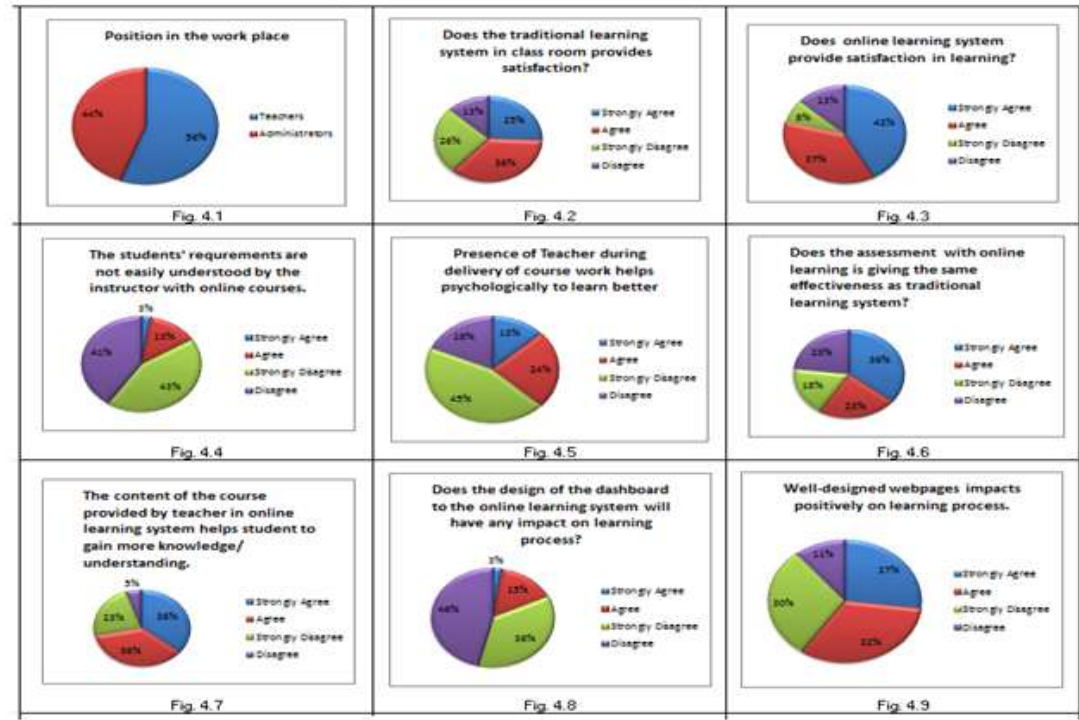

Fig. 4 Results of the Survey 
Table 1 Teachers and Administrator Responses with pie chart

\begin{tabular}{|c|c|c|}
\hline Answer & Response Percentage & \\
\hline Strongly Agree & $49 \%$ & \\
\hline Agree & $30 \%$ & \\
\hline Strongly Disagree & $13 \%$ & w Strongly Agree a Agree ustrongly Disagree a Disagree \\
\hline Disagree & $8 \%$ & \\
\hline
\end{tabular}

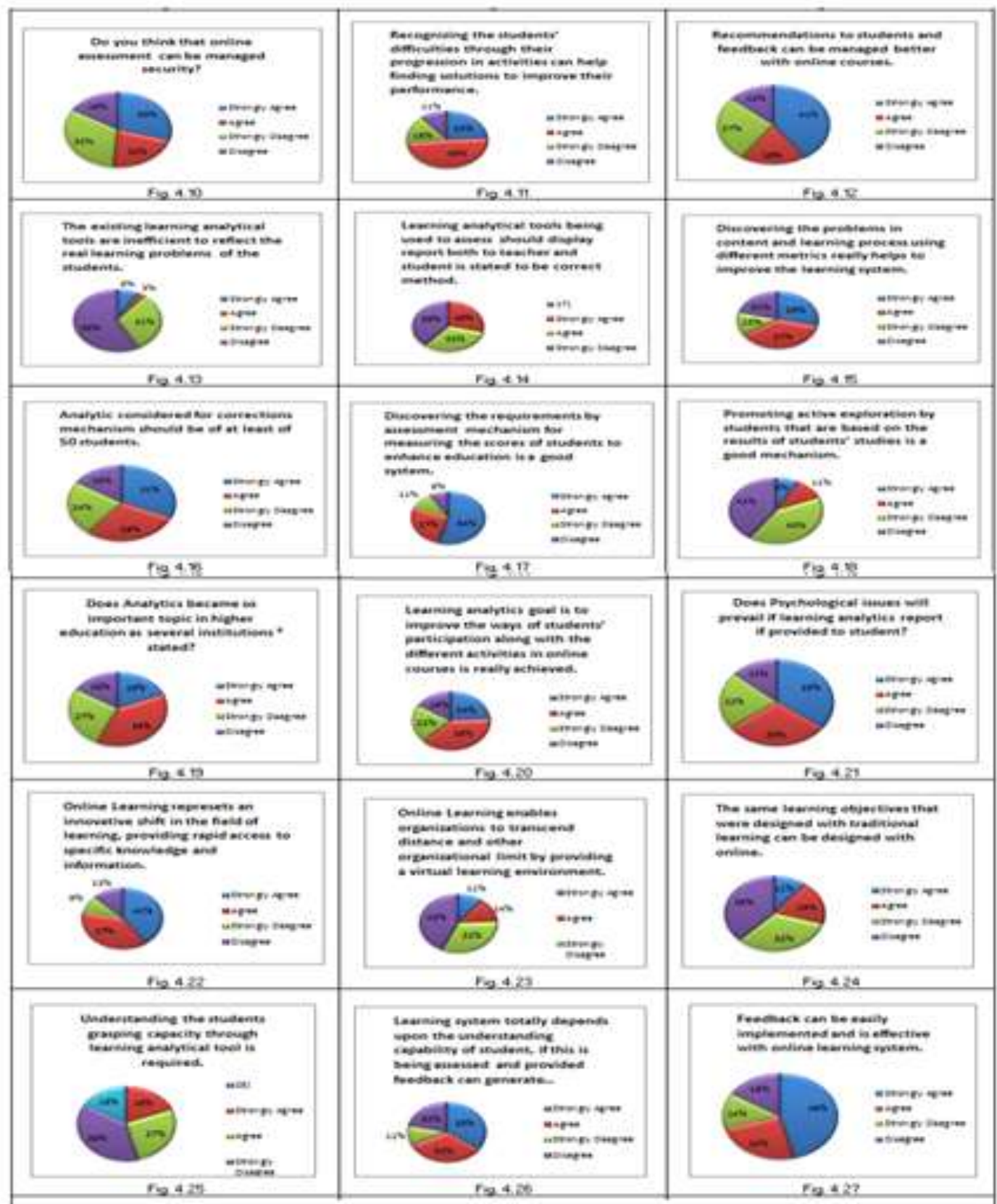

Fig.4.1. Results of the Survey 


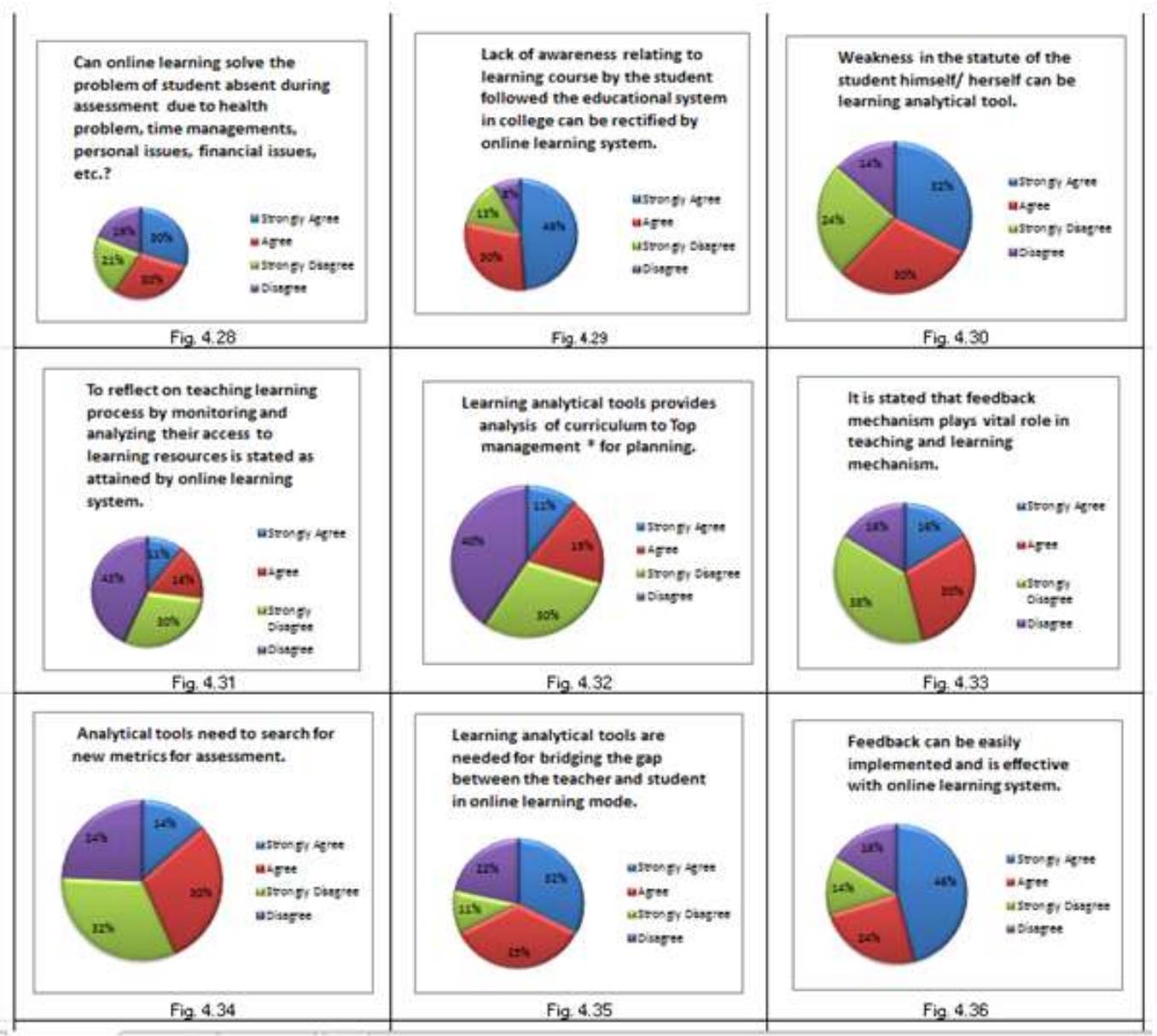

Fig. 4.2 Results of the Survey

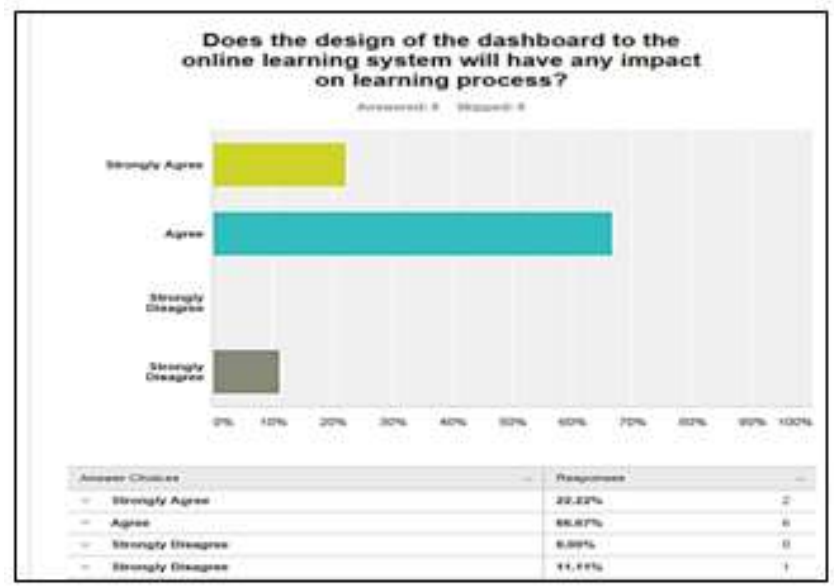

Fig. 5 Question Eleven Bar Chart

\section{Conclusion}

Learning Analytics is not new topics. It became developing in several fields of the educational institutions and business intelligence and so on. The new things are increasing amount and quality of data that pick up and related of learners from over the world and participation in variety of learning processes. Currently learning analytics has more interesting in the learning field because it seeks to obtain the best information and capability to collect the data directly and modify the learning mechanism, thus help the teacher to use the data to update her/ his teaching style and method that required for student's needs in the best way. The improving of use a big data become so rapidly that is by using tools and methods with a new process of management and measurement. So this is called as business intelligence that will assist and support to build and communicate with data with both categories that are learning and academic analytics which had shown in the table below: 
Table 2 Learning and Academic Analytics

\begin{tabular}{|c|c|c|}
\hline TYPES OF ANALYTICS & LEVELOI ANALYTICS & WHO HENEATIS? \\
\hline \multirow[t]{2}{*}{ Learning Anatytien } & $\begin{array}{l}\text { Personal Level: it is related to the } \\
\text { personal's performance which according to } \\
\text { its aim and resource learning. } \\
\text { Courae Level: It is related to social network } \\
\text { and conceptual enhancement. }\end{array}$ & Teachers and Student: \\
\hline & $\begin{array}{l}\text { Departmental Level: It in a way to identify } \\
\text { and predictive the pattems of successes and } \\
\text { failures. }\end{array}$ & Students/Educaton \\
\hline Academic Analytics & $\begin{array}{l}\text { Instifutional: Student 's profile, academic's } \\
\text { performance, ibaring's resource and } \\
\text { knowledge. }\end{array}$ & Administraton \\
\hline
\end{tabular}

Learning analytics will measure, collect, analyze and displays the report data of each student into students participate through the activities of the course material. Its aim is to understand and know the learner pattern studies to identify the learner performance. Effectiveness that happened through the using process of educational learning and resources that helps to make the sense. The benefit of using learning analytics dashboard will help to improve the students' performance, teachers' time and effort that is by providing the information on which student's needs to gain good knowledge and enhance skills. The achievement goals of learning become more rapidly through providing the accessible tools to let the learners and educators to evaluate their performances progress and get the best result. "The benefit of learning analytics assists to enhance the teaching and learning to the teachers to make the students' understanding well", [2]. In addition to that learning analytics helps and supports the educational institutions to achieve the students' performance. The enhancement of a good knowledge is based on the types of education that has followed in the both of learning analytics technique and data mining communities in the educational institutes. From a proper analysis of positive points and constraints on the component, it can be safely concluded that the product is a highly efficient GUI based component. This application is working properly and meeting to all user requirements. This component can be easily plugged in many other systems.

\section{References}

[1] Aguilar, S..L.S..\&.T.S.D., Perceptions and use of an early warning system during a higher education transition program. Learning analytics and knowledge, vol. fourth international conference on learning analytics and knowledge, 2014, $113-117$.

[2] Eckerson, W.W., Performance dashboards: measuring, monitoring, and managing your business. Information Sciences and Computing Technologies, 2010.

[3] Team, E., How Can Educational Data Mining and Learning Analytics Improve and Personalize Education?, 18 Jun,2013

[4] Santos, J.L..G.S..V.K..\&.D.E., Goal-oriented visualizations of activity tracking: a case study with engineering students', learning analytics and knowledge, 2012, 143-152.

[5] Duval, ELearning analytics for visualization and recommendation, Learning Analytics and Knowledge, 2011, 9-17. 